\title{
Racial issues and the multicultural society
}

The background to racial problems in the UK

Descriptions of the main pieces of race legislation

The features and importance of the Stephen Lawrence case

The importance of the Macpherson and Ousley Reports

The work of the Commission for Racial Equality

The broad issues of racial discrimination

Forms of non-legislative race relations initiatives

The issue of multiracialism

\section{IMMIGRATION}

Although Britain has, throughout its history, assimilated large numbers of different ethnic groups from abroad, the issue of race was not a particularly significant element in politics until the 1950s. There were two reasons for this: Firstly, the incoming groups were small and tended to lose their own cultural identity quickly, becoming, within two or three generations, effectively British. Apart from the small Jewish community, many of whom do retain a strong separate identity, most immigrant groups until the 1950s were thoroughly absorbed. Secondly, skin colour had not been a factor until that time. There were small communities of Afro-Caribbean descent, a few residents from the Indian sub-continent and groups of Chinese immigrants, but they had been insignificant in size or impact. Then everything began to change in the second half of the 1950s.

The first significant wave of non-white immigration occurred in the 1950s. This was a time of full employment and there were significant shortages of labour in such fields as the health service and public transport. To meet the shortages, the government introduced a system of subsidised immigration, most from the West Indies. With expenses paid, the new immigrants were 
promised good wages, decent housing and guaranteed employment. Many thousands took up the offer. Immigration from the West Indies has continued ever since, though strict quotas have been set and the cash incentives no longer exist.

The second wave of immigrants arrived in the 1960s and 1970s. These were of Asian descent, either from India and Pakistan (later also Bangladesh), former members of the British empire and therefore British passport holders. In addition to these economic migrants seeking a better life, there were refugees from East Africa, mostly Uganda and Kenya. These groups, also originally from the sub-continent, but largely running businesses in Africa, suffered persecution at the hands of newly independent regimes. Forced out of their adopted countries, and often having their businesses confiscated, these Asians found a natural home in the UK.

Since then immigration has become more diffuse. The numbers are less than in the 1950s to 1970s, but the origins of immigrants have widened. The immigration 'mix' now includes Africans, West Indians, Sub-continent Asians, Hong Kong Chinese and refugees and asylum seekers from all over the world. In the 1990s and early twenty-first century, there has been a large inflow from the Balkans, East Africa, Eastern Europe and even Afghanistan.

\section{IMMIGRATION CONTROL}

In the 1950s there was no thought of the need to control immigration. Indeed, as we have seen, most of the immigrants had actually been invited to settle in the UK. However, as unemployment began to rise in the 1960s and the flow of immigration showed little sign of abating, demands grew for some controls on the numbers entering. In 1958 race riots in London, Nottingham and Liverpool broke out, demonstrating the fears that were beginning to emerge, especially among white members of the working class in cities, where jobs were under threat.

The response of governments of both the main parties was to introduce numerical controls to stem the flow. Commonwealth Immigration Acts in 1962 and 1968 introduced quotas. The Immigration Act of 1971 broadened the controls to non-Commonwealth countries. However it was the 1981 British Nationality Act which represented the most stringent measure to date. This Act remains the basis of immigration policy to the present day. The Act stated that possession of a British passport no longer entitled the holder to residence in the UK. At a stroke many millions of people all over the Commonwealth - i.e. former British colonial possessions - who believed themselves to be partly 
British, were no longer allowed to come to the UK. Residence in the UK would only be allowed to those who could show that they, a parent or a grandparent were born in the UK. The only other way to obtain full nationality and residency rights was to apply for naturalisation after seven years living in the country.

The Nationality Acts of 1962 and 1968 were highly controversial and were the first pieces of legislation which were thought to be 'racist' in their effect (though governments argued they were not racist by intention). The reason was that their effect mostly fell upon Afro-Caribbean and Asian peoples - i.e. so-called 'coloureds'. Would-be white skinned immigrants from Australia, New Zealand, Canada or South Africa could usually find at least a British born grandparent to give them residency rights. This was more rarely the case with black and Asian immigrants.

\section{THE RACIAL QUESTION}

In the 1950s and 1960s racial tensions in Britain grew, very much in proportion to the quantity of immigrants entering the country. Immigrant groups were openly attacked in the race riots of 1958, especially in the Notting Hill district of London. Discrimination against black immigrants was becoming a major cause for concern. Thus was most common in employment, housing, education and social life. But matters reached a head in 1968.

In that year immigration of Asians from East Africa was reaching a peak. The government was proposing more controls on the numbers. A leading Conservative, Enoch Powell, during the debate on the new Immigration Bill, gave a speech in Birmingham (where many of the new immigrants were settling) which was to echo throughout Britain. With a dramatic piece of imagery he claimed, 'like a Roman I seem to see the river Tiber foaming with much blood'. The reason for his vision, he said, was the result of excessive immigration leading to racial violence. The speech, which has come to be known as the 'rivers of blood speech', created a furious response.

On the one hand, Powell claimed to receive 100,000 letters of support for his views. The right-wing press seized on the statement in their campaign to see strict limits on immigration. The Conservative party (led at the time by Ted Heath), where Powell did have a certain degree of support, was forced to sack him from the shadow cabinet. In parliament, where the second Race Relations Act was being debated, MPs on both sides of the divide were galvanised into a major conflict over immigration policy. The speech contributed to the effective end of Powell's political ambitions, but he had set the scene for debates on race for many years to come. 
The Conservatives remained split on the issue, but official policy remained that while immigration quotas should remain, there was to be no repatriation of immigrants. Repatriation was a policy of both the right wingers in the Conservative party and extremists such as the National Front, but it was never seriously considered by political parties. Labour and the Liberals, meanwhile, were committed to improving the state of race relations in the country.

\section{Immigration attitudes}

- Liberal Conservatives and Labour. Support the idea of a multi-racial society with tolerant attitude to racial minorities and accepting racial diversity. Tolerant attitude to asylum seekers. Immigration to be continued, but controlled to reduce over-population and to import people who can reduce skill shortages.

- Centre Conservatives. Support controls on immigration, but allowing some to enter under strict quotas. Insist that racial minorities should learn to integrate.

- Right-wing Conservatives. They have opposed immigration and supported repatriation of immigrant groups. Suspicious of the idea of a multi-racial society, they take a hard line on asylum seekers.

- Liberal Democrats. Strongly believe in a tolerant, multi-racial society. They have an open policy towards asylum seekers and economic refugees. They favour stronger race discrimination laws.

\section{LEGISLATION ON RACE}

The Labour party which came to power in 1965 was committed to improving race relations in Britain. It therefore passed two pieces of legislation.

\section{The Race Relations Act 1965}

This set up the Race Relations Board. The board was to perform two main tasks. Firstly, it was to investigate ways of improving race relations in the country. Secondly, it received complaints from individuals and organisations concerning racial discrimination. It could investigate the claims and recommend measures to overturn the discrimination (positive discrimination).

The board lacked legal powers to enforce its recommendations. However, it did place race racial discrimination

The systematic practice of disadvantaging members of an ethnic group in such fields as employment, social life, supply of service, housing.

positive discrimination

A system which actually

favours members of ethnic groups. For example some jobs or housing will be reserved for such groups. Known as affirmative action in the USA. 
relations on the political agenda and did highlight the worst examples of racism or discrimination.

\section{Race Relations Act 1968}

This Act gave the Race Relations Board some enforcement powers, in particular it could bring to an end any systematic examples of discrimination.

A Community Relations Commission was also established. This commission was to look at the broader picture of race relations. It made recommendations concerning education, employment and housing to try to ensure that members of ethnic minorities received fair treatment.

racism

A generalised attitude which views some racial groups as inferior. It leads to discrimination and sometimes race hatred.

\section{racialism}

Scientific or quasi-scientific theories about race. Most theories suggest that some races are superior to others. The German Nazis and South African white supremacists were examples.

The two Race Relations Acts were certainly progressive on the issue of race. However, in both cases they lacked teeth and failed to make serious inroads into public attitudes. Labour had lost power by 1970 so further progress was put on hold. The Conservatives were not so concerned with racial issues and so relied on the board and the commission to try to keep the lid on race relations. When Labour returned to power in 1974, race appeared high on the agenda again. A third piece of legislation was therefore introduced.

\section{Race Relations Act 1976}

\section{The Commission for Racial Equality}

Firstly, this tidied up the confusion over the existence of two bodies concerned with racial issues. The Board and Commission were replaced by the Commission for Racial Equality (CRE).

\section{Role of the CRE}

- To advise and assist people and organisations, including the media, on racial issues.

- Investigate discrimination policies by companies, the media and other organisations, requiring them to change as necessary.

- To take legal action against specific discrimination incidents.

- To sponsor judicial reviews by individuals and groups where they feel they have suffered discriminatory practices by a public body.

- To advise the government on possible future legislation and race policy.

- To liaise with local Racial Equality Councils, which have been set up to foster good community race relations.

The Commission has 15 members and a staff of over 200. It has regional offices and is headed by a chairperson. 


\section{The Act and racial discrimination}

For the first time the Act was specific in making certain discriminatory practices illegal. Any action which is considered to be discriminatory (either directly or in its indirect effect) on the basis of race, colour, nationality or ethnic and national origin, is deemed to be illegal. The CRE may prosecute any individual or organisation which contravenes this provision.

Certain areas of activity were specified as applying to the law. These were:

- Employment: in pay, recruitment, promotion or training practices.

- Housing: applying to the allocation of housing by local authorities and housing associations. This also applied to private landlords or estate agents and solicitors involved in sale and purchase.

- Education: schools could not refuse entry on the grounds of race etc. Nor could any racial group be excluded from specific subjects or activities.

- Provision of goods and services: discriminatory practices when selling goods or providing services.

\section{Summary of the Act}

The 1976 Act was undoubtedly the most important development in race relations since World War II. It was important for the following reasons:

1 It established discrimination as a crime.

2 It established the Commission for Racial Equality as a key part of the British political establishment.

3 It widened the areas in which racial discrimination was to be outlawed.

4 It created a powerful pressure group which could campaign for better race relations in the UK.

But the Act had its weaknesses. A number of institutions were exempt, most notably the police. It also could not enforce the law with regard to private organisations such as sports or social clubs. Perhaps most significantly, the Act could only really deal with very specific examples of discrimination. It could not deal effectively with attitudes to race. Nor was it concerned with some of the social causes of racial conflict. Thus, when serious inner city disorders broke out in London, Liverpool, Leeds and Bristol in 1981, the racial undertones were left largely untouched.

Legal measures undoubtedly help to lead public opinion towards a more tolerant society. However, they are insufficient on their own. It was not until the 1976 Act was amended in 2000 that the broader aspects of the race problems were tackled by legislative action. 


\section{ARTICLE 13 OF THE AMSTERDAM TREATY}

This was agreed in 2000 by all EU members. It asserts a minimum standard of legal protection for all ethnic minorities. When the Article became compulsory in 2003 ethnic minorities throughout the European Union were offered the same protection.

The British government take the view that the law in the UK already conforms to Article 13 in most respects, but there may have to be some toughening up of the regulations on policing and the conduct of trials where race is an issue. The additional measures are due to be announced later in 2002.

\section{THE RACE RELATIONS (AMENDMENT) ACT 2000}

This Act came into force in April 2001. It was in part an updating and extension of the 1976 Act, but was also a response to growing concerns about the state of race relations in Britain at the end of the twentieth century. In particular it had to deal with the conclusions of the Macpherson Inquiry into the Stephen Lawrence murder case. The incident and inquiry are described in more detail below. Macpherson uncovered deep problems in race relations in Britain. It had six main measures.

1 It established a code of practice which the CRE tries to promote in public bodies. It applies mainly to the criminal justice system, the police, education, the health service, housing, local government, politics and sport. Best practice is not a statutory (i.e. legally compulsory) requirement, but the CRE is charged with the task of trying to implement it.

The kind of measures included are the education and training of staff on racial equality, eliminating practices which might cause racial discrimination, directly or indirectly, the reporting of racial incidents and future prevention. There was also an implication that ethnic minorities should be given fair representation in recruitment and promotion. However, the last measure was to be beefed up when the Act was amended in 2000 .

2 There was a statutory duty imposed upon all public bodies to promote equality of opportunity and race relations. Government, education, the police and local authorities were the principal examples.

3 Where crimes were considered to have a racial element (such as an assault based on racial conflict) they would be considered to be more serious and the sentences would reflect this. 
4 Incitement to racial hatred (whether or not leading to violence) was made a serious offence. This was particularly aimed at publicity produced by such extreme groups as the British National Party.

5 Police officers were made vicariously liable for racial offences committed by the police. In other words more senior officers can now be held legally responsible for the actions of their subordinates, whether or not they are directly involved.

6 A race legislation unit within government was set up to oversee the implementation of the Act

The 2000 Act did, therefore, attempt to fill in some of the gaps left by the 1976 legislation. It extended the provisions, outlawed more general examples of racial conflict and introduced statutory duties on organisations to improve their race relations record. Its main effect will be felt by the police. This is because the Act had to respond to the Macpherson Report (see below). Nevertheless it has created a climate in which all public bodies now feel they have a responsibility to improve race relations and racial equality.

Above all, however, the 2000 Act has shifted the whole emphasis on race relations. In the past the stress has been placed on dealing with racism by making discriminatory activities unlawful. Following the Macpherson Report and the 2000 Act there is a statutory duty upon many organisations to advance good race relations in a positive way. As we shall see below too, non-legislative measures have tended to concentrate on positive measures and not just negative prevention.

\section{THE STEPHEN LAWRENCE INQUIRY (MACPHERSON)}

At first sight the Stephen Lawrence case and inquiry represented a tragic incident which had little impact outside south London. In fact, the case proved to be something of a turning point in race relations in Britain.

On 22 April 1993 Stephen Lawrence, a black teenager, was murdered in south London by a group of white youths. The murder seemed to have no motive, but it was later established to be racially motivated. Though the guilty men were widely known in the area, the police failed to secure a prosecution. It was claimed that the police had made insufficient efforts to secure a conviction, had failed to offer sufficient protection to witnesses and had failed to understand the racial nature of the crime. The Lawrence family, encouraged by the $\mathrm{CRE}$ and other race relations campaigners, called for an inquiry into the case 
and the government acceded to the request by convening a commission under Sir William Macpherson to investigate.

His report in February 1999 had an extraordinary impact. Its effects can be seen on two levels:

\section{The police and institutional racism}

Macpherson declared that the Metropolitan Police, who had investigated the case, were characterised by what he called institutional racism. Thus a new phrase entered the vocabulary of race relations. The definition in the report was as follows:

\section{institutional racism}

'[Institutional Racism] consists of the collective failure of an organisation to provide an appropriate and professional service to people because of their colour, culture or ethnic origin. It can be seen or detected in processes, attitudes and behaviour which amounts to discrimination, through unwitting prejudice, ignorance, thoughtlessness and racial stereotyping which disadvantages minority ethnic people.'

There had long been strong suspicions that the police contained racist elements, but Macpherson went further. He suggested that racist attitudes were deeply ingrained in the force and in its institutions. In other words it was part of the culture of the institution. The implications for race relations were, of course, very serious. The CRE had already pointed to lack of trust between ethnic minority communities and the police. Macpherson confirmed this and demonstrated how deeply established the problem was. Indeed Macpherson suggested that, as the police were part of the problem, they also had to be part of the solution.

There was also an implication that other institutions might also suffer from institutional racism. He therefore made a general statement with them in mind:

It is incumbent upon every institution to examine their policies and the outcome of their policies and practices to guard against disadvantaging any section of the community.

The Race Relations (Amendment) Act of 2000 responded to this conclusion. The police service was required to introduce a number of measures, known as the Police Action Plan. They included:

- Education for police officers to prevent racially motivated actions. Awareness of possible racial problems in policing to be raised.

- Efforts were to be made to ensure that recruitment, retention and promotion policies are non-discriminatory. 
- The recording of all racial incidents.

- Logging of all 'stop and search' incidents to ensure that there was no systematic discrimination against ethnic minorities.

- Strict disciplinary procedures were introduced against officers guilty of racial prejudice.

\section{Community race relations}

The Lawrence murder had once again drawn attention to the sorry state of race relations in poorer districts of big cities. To some extent, Macpherson asserted, this was due to lack of trust between the community and the police. His recommendations were designed to reduce such suspicions. However, the report went further.

Macpherson recommended that racially motivated crimes should be singled out for special attention. Where there was a racial element, sentencing was to be more severe. Furthermore all racial incidents, whether or not they resulted in a crime, were to be recorded by the police. A racist incident was defined by Macpherson as: 'any incident which is perceived to be racist by the victim or any other person'.

The police were not the only body to be singled out as playing a crucial role in community relations. Macpherson also stressed the need for a multi-agency approach to improving race relations at local level. Local councils, schools, social services, community leaders and the police were urged to work together to build trust among different ethnic groups.

On a national level the government's Race Equality Unit of the Home Office responded to Macpherson by producing 'public service agreements' with a variety of institutions. The central plan was to see progress towards 'representative' workforces (i.e. containing appropriate proportions from members of ethnic minorities). The institutions concerned included the police, fire, probation and prison services. These bodies stand at the forefront of race relations so that their race policies are crucial.

As we have seen, the impact of Macpherson was far-reaching. As the twentyfirst century dawned, therefore, there were renewed hopes for race relations in Britain. Sadly these hopes were dashed in the summer of 2001 by racial conflict in a number of northern cities.

\section{THE 2001 RIOTS AND THE OUSELEY REPORT}

In July 2001 serious rioting broke out in a number of cities including Burnley, Oldham and Bradford. The problem was largely confined to white and Muslim 
youths who engaged in organised fighting and damage to property. The former Chairman of the Commission for Racial Equality, Sir Herman Ouseley, was immediately asked to make an inquiry and he reported rapidly on the incidents. His report was entitled, ' Community Pride, Not Prejudice'.

\section{Community pride, not prejudice}

Ouseley was addressing an issue which had become central to race in Britain at the beginning of the twenty-first century. This was a twofold problem:

1 Assuming that a multi-racial society is desirable, how should we define the term 'multicultural'?

2 Having established the nature of a multicultural society, how should we go about achieving it?

The answer to the first question was that a multicultural society is one where all ethnic groups feel integrated and included. In other words, although cultural differences should be tolerated and protected, it is desirable for all groups to integrate into mainstream British culture. This image is very much how traditional Jewish communities in Britain have dealt with the problem. Ouseley was also suggesting that the reason why youths from ethnic minorities (mainly Muslim in the case of the 2001 riots) were so disaffected was that they felt alienated from British society. It was not so much that they experienced direct discrimination, but that they felt excluded.

The second question is clearly more complex. However, in general terms Ouseley was proposing that each community had a responsibility to promote full integration and to prevent any group feeling excluded. In practical terms this would mean finding ways of bringing ethnic communities together, but more importantly, it required a widening of opportunity for those members of ethnic minorities who experience the alienation. If these objectives could be achieved, all members could share in 'community pride'.

\section{An alternative view}

An alternative view of what a multi-cultural society is, which can be broadly described as 'liberal' in nature, is rather different. This view suggests that, in a truly multicultural society, cultural differences should be preserved and celebrated. Within such a scenario, each ethnic group should tolerate the different cultures which flourish, but should not seek full integration.

This vision sees diversity as a positive force, increasing the richness of society and actually encourages tolerance. In practice, it implies the creation of more single-faith schools which preserve different cultures and the strong protection of minority rights against discrimination and antagonism. 
Members of so-called 'ethnic minorities' should still be required to be good citizens, with all the responsibilities which that carries. However, as far as possible, cultural differences should be protected by the law (notably the European Convention on Human Rights) and positively encouraged.

\section{THE RACE EQUALITY UNIT}

This is a government body which was set up to implement Labour's race relations policy. Its view of a multicultural society is very much along the lines of the second vision described above - that ethnic differences should be allowed to flourish, but that each group should have an equal stake in society and should be free from discrimination. The 'mission statement' of the race equality unit very much epitomises the Labour government's view of good race relations. It says that Britain should be a country where:

multiculturalism

Ideas which suggest that society should tolerate ethnic diversity or should encourage full cultural integration.

- Every colour is a good colour.

- Every member of society is able to fulfil their potential.

- Racism is unacceptable.

- Everyone is treated equally according to needs and rights.

- Everyone recognises their responsibilities.

- Racial diversity is celebrated.

This is a clear enough statement of what is considered to be a fair and healthy multicultural society. A particularly practical step has taken place within the Home Office where there is an agreement to create 'representative' workforces in the police, fire, probation and prison services.

\section{NON-LEGISLATIVE RACIAL MEASURES}

Most of the attempts to outlaw racism and racial discrimination in Britain have involved legislation, either to prohibit discriminatory practices or to require institutions to improve race relations. However, dealing with this issue is too complex to be handled through the law alone. There have also been a number of initiatives designed to change attitudes, consciousness and behaviour. In other words there is a need to create a new culture of race relations. Some of the objectives of these programmes have been:

- to create equality of opportunity for all racial and national groups;

- to eliminate racist attitudes and so reduce racial violence;

- to foster better relations between different ethnic groups; 
- to make Britain an inclusive society in which all groups feel they have a stake;

- to create a climate of tolerance towards an ethnically diverse society.

A wide variety of measures are in place to try to achieve these objectives, mostly under the auspices of the Commission for Racial Equality. However many other agencies are involved. These include the football authorities who have instituted a programme to remove racism from the game, local authorities, educational bodies and the Civil Service itself.

Ironically it is in the field of politics where there has been a noticeable lack of progress. There are still very few MPs from ethnic minority backgrounds (though the number is creeping up). The battle to have separate black sections' within the Labour party failed. This would have ensured guaranteed representation on party bodies for ethnic minority members. It would also have increased the number of parliamentary candidates and therefore MPs. The House of Lords, which is supposedly a socially representative chamber has also lagged behind. The new Appointments Commission is, however, charged with the task of ensuring the nomination of more peers from different ethnic groups. The Civil Service code of practice also now demands progress towards more racial equality in recruitment and promotion.

However, it is likely that education is the main field in which better race relations and equality of opportunity will be achieved. The National Curriculum recognises this and every local education authority has a duty to improve race relations. Unfortunately, by 2002, there was still no clear policy on whether schools should be more ethnically mixed or whether it was better to encourage the creation of more single-faith schools. There are many who believe that the latter will reinforce ethnic tensions, while others suggest that such schools actually prevent them.

Table 8.1 Britain's ethnic mix, 2001

\begin{tabular}{lc}
\hline Ethnic group & Millions \\
\hline White & 53.0 \\
All black groups & 1.3 \\
Indian & 1.0 \\
Pakistani/Bangladeshi & 0.9 \\
Chinese & 0.1 \\
Others & 1.5 \\
All non-white & 4.8 \\
\hline
\end{tabular}




\section{SAMPLE QUESTIONS}

1 Discuss the significance and impact of the Macpherson Report into the Stephen Lawrence case.

2 What have been the main barriers to improving race relations since the 1960s?

3 Differentiate between legislative and non-legislative methods of

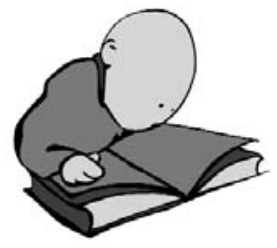
improving race relations.

4 What have been the attitudes of the main parties in Britain towards race relations and immigration?

5 Describe the role of law in the field of race relations. 